\title{
ISOFLAVONAS EM ISOLADOS E CONCENTRADOS PROTÉICOS DE SOJA ${ }^{1}$
}

\author{
Maria Cristina Y. LUI ${ }^{2}$, Cláudio L. AGUIAR ${ }^{3}$, Severino M. de ALENCAR ${ }^{4}$, \\ Adilma Regina P. SCAMPARINI ${ }^{5}$, Yong K. PARK ${ }^{6, *}$
}

\section{RESUMO}

Isolados e concentrados protéicos de soja são ingredientes largamente utilizados na indústria de panificação, confeitaria, bebidas e embutidos. As isoflavonas presentes na soja podem sofrer alterações em quantidade e perfil de distribuição dependendo das condições de processamento. O objetivo deste estudo foi verificar o balanço de massa de isoflavonas e proteína em processamento de isolados e de concentrados protéicos de soja (tratamento com ácido e com álcool). A maior parte das isoflavonas presentes na matéria-prima (farinha desengordurada de soja) é perdida nos sobrenadantes de processo (90\% para extração com etanol 60\%, 52\% para processamento de isolado protéico e $47 \%$ para extração com ácido). O teor de isoflavonas nos produtos obtidos foi de $686 \mu \mathrm{g} / \mathrm{g}$ base seca (b.s.) para isolado protéico, $871 \mu \mathrm{g} / \mathrm{g}$ b.s. para concentrado protéico obtido por tratamento ácido e apenas $153 \mathrm{\mu g} / \mathrm{g}$ b.s. para concentrado protéico obtido por tratamento com álcool. Não foi observada alteração no perfil de distribuição das isoflavonas nesse último processo, enquanto que nos dois primeiros notou-se diminuição da quantidade das formas malonil glicosídeos e aumento da quantidade das formas $\beta$-glicosiladas e gliconas. Palavras-chave: isoflavonas; balanços de massas; isolado protéico de soja; concentrado protéico de soja.

\section{SUMMARY}

ISOFLAVONES IN SOY PROTEIN ISOLATE AND SOY PROTEIN CONCENTRATE. Soy protein isolate (SPI) and soy protein concentrate (SPC) are largely used in bakery, confectionary, meat and beverage products. Isoflavones present in soybeans products can undergo changes in quantity and profile depending on the processing conditions. The objective of this work was to conduct mass balance studies of isoflavones and protein during the processing of SPI and SPC (acid and alcohol leach). The majority of isoflavones present in the raw material is lost in the supernatants (90\% for SPC treated with alcohol, $52 \%$ for SPI and $47 \%$ for SPC treated with acid). Total concentration of isoflavones was $652 \mu \mathrm{g} / \mathrm{g}$ for SPI, $838 \mu \mathrm{g} / \mathrm{g}$ for SPC (acid leach), and only $147 \mu \mathrm{g} / \mathrm{g}$ for SPC (alcohol leach). There were no changes in the profile of isoflavones in this last process, whereas in the previous two, the amount of malonyl glycosides decreased while the total amount of $\beta$-glycosides and aglucones significantly increased.

Keywords: isoflavones; mass balance studies; soy protein isolate; soy protein concentrate.

\section{1 - INTRODUÇÃO}

A soja e seus derivados apresentam grande potencial no mercado de alimentos funcionais devido à presença de compostos bioativos, como as isoflavonas, as quais têm sido largamente estudadas quanto aos seus efeitos biológicos benéficos à saúde humana, tais como: atividade estrogênica [15], antiestrogênica (especialmente sobre os sintomas da sindrome de climatério e da osteoporose) [8, 14, 20], hipocolesterêmica [2] e anticarcinogênica [6, 7, 12]. Os grãos de soja podem conter até doze tipos de isoflavonas: as formas agliconas daidzeina, gliciteina e genisteína (Figura 1); e os $\beta$-glicosídeos conjugados: daidzina, glicitina, genistina, acetil daidzina, acetil glicitina, acetil genistina, malonil daidzina, malonil

\footnotetext{
Recebido para publicação em 10/01/2003. Aceito para publicação em 10/09/2003 (001057).

${ }^{2}$ Laboratório de Bioquimica, Faculdade de Engenharia de Alimentos, UNICAMP.e-mail: cristina.lui@uol.com.br

${ }^{3}$ Laboratório de Bioquimica, Faculdade de Engenharia de Alimentos, UNICAMP.e-mail:claguiar@yahoo.com.br.

${ }^{4}$ Laboratório de Bioquimica, Faculdade de Engenharia de Alimentos, UNICAMP.e-mail: smalencar@netscape.net

${ }^{5}$ Laboratório Geral de Alimentos, Faculdade de Engenharia de Alimentos, UNICAMP.

${ }^{6}$ Laboratório de Bioquimica, Faculdade de Engenharia de Alimentos, UNICAMP. R. Monteiro Lobato, 80. Cx Postal 6121. Campinas, SP. CEP 13083-970.e-mail:ykpark@fea.unicamp.br

* A quem a correspondência deve ser enviada
}

glicitina e malonil genistina (Figura 2) [13]. XU et al. [26], demonstraram que as isoflavonas glicosiladas não são absorvidas diretamente, fato comprovado por SETCHELL et al. [21]: isoflavonas glicosiladas sofrem hidrólise prévia a agliconas por ação de $\beta$-glicosidases intestinais antes de serem absorvidas pelo organismo humano.

As isoflavonas podem sofrer transformações durante o processo de fabricação de ingredientes e alimentos à base de soja, havendo conversão parcial das formas esterificadas para as formas glicosiladas e agliconas [7, 24]. O aquecimento promove a conversão das formas malonil glicosideos a acetil glicosideos, e enzimas do tipo $\beta$-glicosidases, presentes naturalmente na soja ou produzidas por microrganismos inoculados em produtos fermentados podem hidrolisar os $\beta$-glicosideos, liberando glicose e agliconas [17, 24].

Balanços de massa de isoflavonas para processamento de isolados protéicos de soja já foram estudados anteriormente por WANG \& MURPHY [24] e por WANG et al. [25]. Esses estudos, entretanto, não consideraram o rendimento em peso nem o percentual de proteina dos produtos obtidos. PANDJAITAN et al. [16] quantificaram genistina e genisteina em concentrados protéicos de soja obtidos por tratamento ácido e alcoólico, mas somente nas matérias-primas e produtos finais, não analisando os efluentes do processo. 


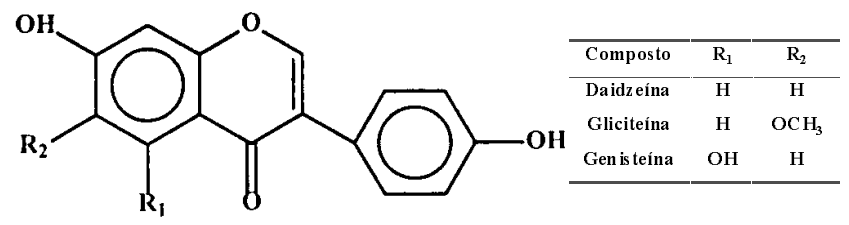

FIGURA 1. Isoflavonas agliconas da soja

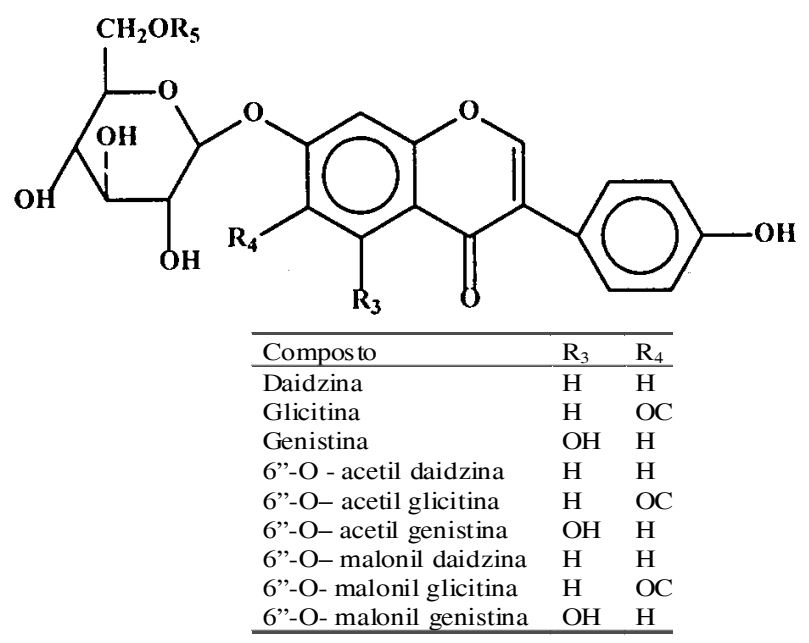

FIGURA 2. Isoflavonas glicosiladas de soja [22].

Este trabalho visou estudar balanços de massa de isoflavonas e proteína em processos de obtenção de isolados e de concentrados protéicos de soja (por tratamento ácido e alcoólico), identificando pontos potenciais para recuperação de isoflavonas.

\section{2 - MATERIAL E MÉTODOS}

\section{1 - Material}

A farinha desengordurada de soja não tratada termicamente foi cedida pela Bunge Alimentos. Os padrões daidzina, genistina, daidzeina e genisteina foram comprados da Sigma Chemical Co. Todos os reagentes e solventes usados foram de grau analitico ou para cromatografia liquida.

\section{2 - Métodos}

\subsection{1 - Obtenção de isolado protéico de soja}

O isolado protéico de soja foi preparado conforme o método de WANG et al. [25], com adaptações para condições de otimização de rendimento protéico [4], como ilustrado na Figura 3. Primeiramente, $50 \mathrm{~g}$ de farinha desengordurada de soja (FDS) foram suspendidas em $1 \mathrm{~L}$ de água destilada, e o $\mathrm{pH}$ da mistura ajustado para 9,0 por adição de solução de $\mathrm{NaOH} 4 \mathrm{~N}$. O tempo de extração foi de 45 minutos a $55^{\circ} \mathrm{C}$, sob agitação. A suspensão foi centrifugada a $13.000 \mathrm{x} \mathrm{g}\left(25^{\circ} \mathrm{C}\right)$ por $20 \mathrm{mi}-$ nutos (Centrífuga Beckman, modelo J-21), e o residuo coletado e liofilizado. O sobrenadante teve o $\mathrm{pH}$ ajustado para 4,5 por adição de solução de $\mathrm{HCl} 6 \mathrm{~N}$, sofrendo agitação por 1 hora à temperatura ambiente. A seguir, a suspensão foi centrifugada novamente por 20 minutos a $13.000 \mathrm{x} \mathrm{g}\left(5^{\circ} \mathrm{C}\right)$, e o precipitado (isolado protéico) coletado e liofilizado. O sobrenadante foi dividido em aliquotas: uma para liofilização e quantificação de isoflavonas e outra para determinação de proteínas.

\subsection{2 - Obtenção de concentrado protéico de soja por tratamento ácido}

O concentrado protéico de soja isoelétrico foi obtido pelo método descrito por ZANGELMI et al. [27], conforme mostrado na Figura 4. 50g de farinha desengordurada de soja foram suspensos em $1 \mathrm{~L}$ de água destilada, e o pH da suspensão ajustado para 4,5 por adição de solução de $\mathrm{HCl} 6 \mathrm{~N}$. Após agitação por 1 hora à temperatura ambiente, a mistura foi centrifugada por 20 minutos a $13.000 \mathrm{xg}\left(5^{\circ} \mathrm{C}\right)$, e as frações coletadas e liofilizadas para análises posteriores.

\subsection{3 - Concentrado protéico de soja por trata- mento alcóolico}

O concentrado protéico foi preparado segundo o método de CAMPBELL et al. [5], alterando-se a proporção de farinha desengordurada de soja: solvente de 1:10 para 1:20, a fim de aumentar o rendimento em peso do processo. $50 \mathrm{~g}$ de farinha desengordurada de soja foram dispersas em $1 \mathrm{~L}$ de etanol $60 \%$ (v/v), sofrendo agitação por 1 hora à temperatura ambiente. Em seguida, a suspensão foi centrifugada por 20 minutos a $13.000 \mathrm{x} \mathrm{g}$ $\left(5^{\circ} \mathrm{C}\right)$, e o precipitado coletado e liofilizado. O sobrenadante também foi coletado para posterior quantificação de isoflavonas e determinação de proteinas.

\subsection{4 - Extração de isoflavonas}

As amostras liofilizadas (1g para amostras sólidas e $0,5 \mathrm{~g}$ para sobrenadantes) foram extraídas com 10 volumes de metanol $80 \%$ (v/v) por $1 \mathrm{~h}$ à temperatura ambiente, em tubos fechados sob agitação [19]. A seguir, as amostras foram centrifugadas a $5.500 \mathrm{xg}$ por $10 \mathrm{mi}-$ nutos e o sobrenadante filtrado em membrana de $0,22 \mu \mathrm{m}$ de poro (Millipore).

\subsection{5 - Determinação de isoflavonas por CLAE}

Os extratos metanólicos foram analisados pro CLAE em fase reversa, de acordo com o método descrito por PARK et al. [18]. Aliquotas de $20 \mu \mathrm{L}$ foram injetadas automaticamente em cromatógrafo líquido, equipado com arranjo de fotodiodos (SPD-M10 AVP, Shimadzu Co.) e

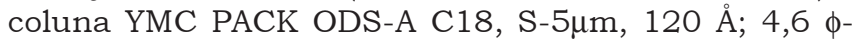
$250 \mathrm{~mm}$. Condições cromatográficas: temperatura da coluna de $30^{\circ} \mathrm{C}$, fluxo de $0,5 \mathrm{~mL} / \mathrm{min}$. A fase móvel (solvente A) consistiu de uma mistura de água:ácido acético (19:1), enquanto o solvente B usado foi metanol. O gradiente foi iniciado com $20 \%$ de solvente B, passando para $40 \%$ em $15 \mathrm{~min}$, subindo a $50 \%$ entre 15 e 55 min, atingindo $80 \%$ em $95 \mathrm{~min}$, decrescendo para $20 \%$ 
entre 95 e 105 min. A coluna foi reequilibrada com $20 \%$ de B por 15 min entre as corridas. A detecção foi feita pela absorção a $254 \mathrm{~nm}$. As concentrações de daidzina, genistina, daidzeina e genisteína foram calculadas por suas curvas-padrão. Glicitina e seus conjugados foram calculados pela curva-padrão daidzina $[3,7]$. As concentrações dos malonil e acetil conjugados foram calculadas a partir das respectivas curvas-padrão de daidzina e genistina. Os valores foram normalizados considerando-se as diferenças de peso molecular das formas glicosiladas, multiplicando-se a massa de cada derivado pela razão entre o peso molecular da respectiva aglicona e o peso molecular da forma glicosilada [22].

\subsection{6 - Determinação de proteinas}

O teor de proteinas em cada parte do processamento e nos produtos finais foi determinado pelo método semimicro de Kjedahl - AOAC 960.52 [1], usando o fator de conversão de 6,25.

\subsection{7 - Determinação de umidade e teor de sóli- dos}

O percentual de umidade das amostras sólidas foi determinado pelo método AOAC 925.10 [1] e o teor de sólidos das amostras liquidas, pelo método AOAC 920.193 [1].

\subsection{8 - Análise estatística}

Cada processo foi realizado em triplicata, e as amostras geradas em cada fase do processo também analisadas em triplicata. A análise estatística foi feita por meio do software Statistica (versão 5.0, 1995), desenvolvido pelo Statsoft Inc, Tulsa. As diferenças entre as médias foram analisadas pelo teste de LSD $\operatorname{com} \alpha=0,05$. Os resultados foram expressos como média \pm desvio padrão, $\mathrm{n}=3$.

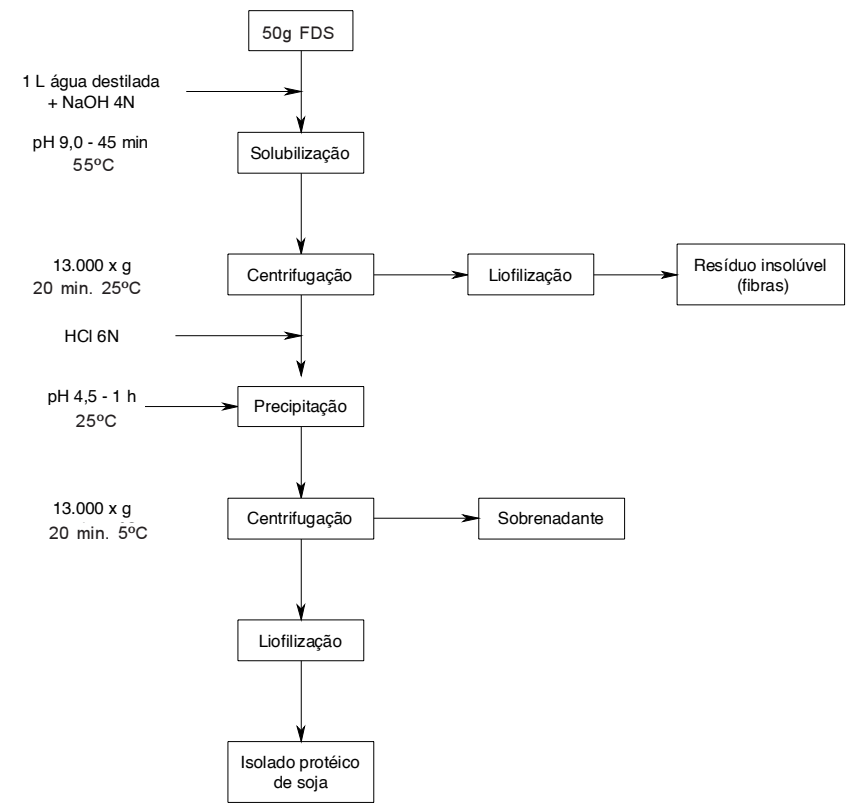

FIGURA 3. Fluxograma de obtenção de isolado protéico de soja

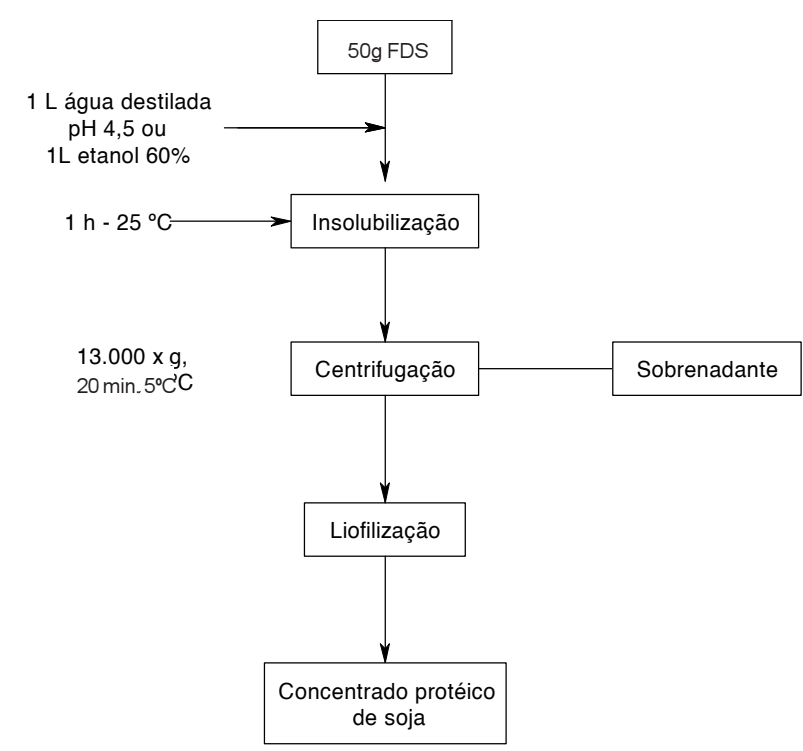

FIGURA 4. Fluxograma de obtenção de concentrado protéico de soja por tratamento ácido/alcóolico

\section{3 - RESULTADOS E DISCUSSÃO}

O rendimento do processo para isolado protéico de soja foi de $38 \pm 1 \%$ em peso por peso (Tabela 1), compativel com os indices indicados por ZANGELMI et al. [27]. Esse rendimento foi maior que o de $17,8 \%$ obtido por WANG \& MURPHY [24] e o de $28,9 \%$ obtidos por WANG et al. [25]. As diferenças no rendimento se devem provavelmente às condições de extração utilizadas, como $\mathrm{pH}$ e temperatura. Enquanto esses autores extraíram a proteína a $\mathrm{pH}$ 8,5 e 8,0, respectivamente, à temperatura ambiente, neste trabalho a proteina foi extraída a $\mathrm{pH}$ $9,0,55^{\circ} \mathrm{C}$, condições descritas como ótimas para extração por BURK [4]. Verificou-se ainda que o produto obtido corresponde à definição de isolado protéico de soja, por apresentar mais de $90 \%$ de proteina $(\mathrm{N} \mathrm{x} \mathrm{6,25)} \mathrm{em}$ base seca. O teor total de isoflavonas $(\mu \mathrm{g} / \mathrm{g}$ base úmidab.u.) encontrado para farinha desengordurada de soja foi inferior ao determinado por GENOVESE \& LAJOLO [10], para matéria-prima do mesmo fabricante. Esses autores analisaram 3 lotes diferentes de farinha, encontrando teores de 1565 a $2032 \mu \mathrm{g} / \mathrm{g}$ (b.u.). A quantidade total de isoflavonas e o perfil de distribuição destas variam com a cultivar, local de plantio, tipo de solo, clima e ano da safra [11, 23, 24]. A diferença no teor encontrado se deve provavelmente à diferença de matéria-prima utilizada, e conseqüentemente, dos lotes de farinha analisados.

A Figura 5 mostra que o sobrenadante, considerado usualmente como descarte, contém mais da metade das isoflavonas presentes na matéria-prima original (farinha desengordurada de soja), fato também observado por ELRIDGE [9] e WANG \& MURPHY [24]. O resíduo insolúvel, composto por fibras, apresenta $38 \%$ de proteina em base seca, e contém $12 \%$ das isoflavonas originais, o que torna interessante seu aproveitamento industrial. 
TABELA 1. Balanço de massa global para processo de obtenção de isolado protéico de soja

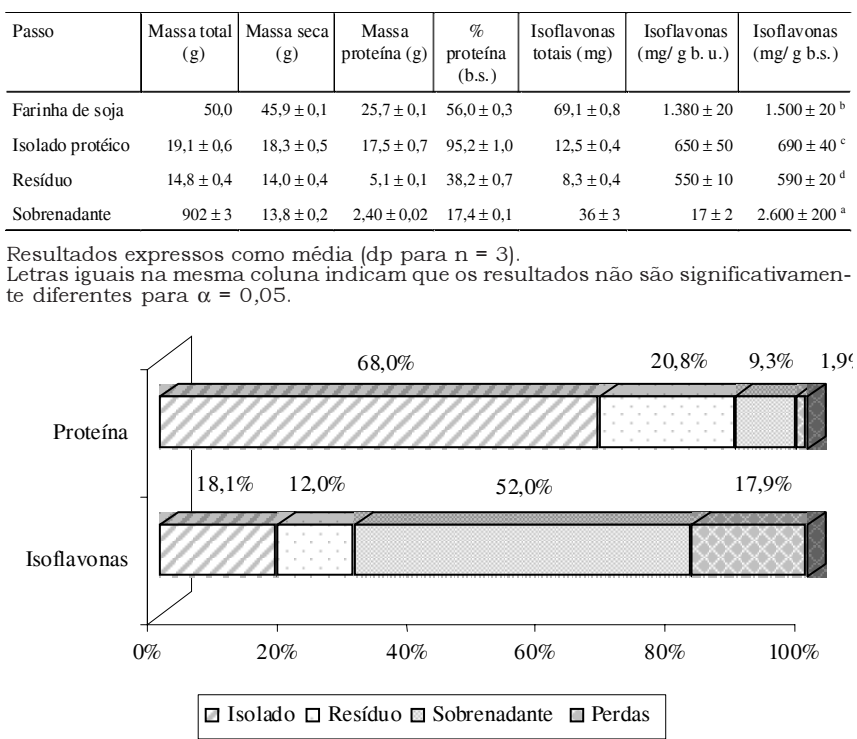

FIGURA 5. Retenção de proteína e isoflavonas nas correntes de processamento de isolado protéico de soja

A Tabela 2 ilustra o perfil de distribuição de isoflavonas para o produto e subprodutos do processo:

TABELA 2. Perfil de distribuição de isoflavonas em processo de obtenção de isolado protéico ( $\mu \mathrm{g} / \mathrm{g}$ b.s.)

\begin{tabular}{lrr|r|r}
\hline \multicolumn{1}{c}{ Isoflavona } & $\begin{array}{r}\text { Farinha de soja } \\
(\mu \mathrm{g} / \mathrm{g} \text { b.s. })\end{array}$ & $\begin{array}{c}\text { Isolado protéico } \\
(\mu \mathrm{g} / \mathrm{g} \text { b.s. })\end{array}$ & $\begin{array}{c}\text { Resíduo } \\
(\mu \mathrm{g} / \mathrm{g} \text { b.s. })\end{array}$ & $\begin{array}{c}\text { Sobrenadante } \\
(\mu \mathrm{g} / \mathrm{g} \text { b.s. })\end{array}$ \\
\hline Daidzina & $211 \pm 6^{\mathrm{b}}$ & $79 \pm 4^{\mathrm{c}}$ & $114 \pm 2^{\mathrm{c}}$ & $550 \pm 50^{\mathrm{a}}$ \\
Glicitina & $29,8 \pm 0,6^{\mathrm{b}}$ & $11,7 \pm 0,8^{\mathrm{c}}$ & $15,1 \pm 0,5^{\mathrm{c}}$ & $110 \pm 10^{\mathrm{a}}$ \\
Genistina & $284 \pm 6^{\mathrm{b}}$ & $165 \pm 10^{\mathrm{c}}$ & $209 \pm 4^{\mathrm{c}}$ & $580 \pm 50^{\mathrm{a}}$ \\
Malonil daidzina & $367 \pm 2^{\mathrm{b}}$ & $98 \pm 9^{\mathrm{c}}$ & $72 \pm 5^{\mathrm{c}}$ & $590 \pm 70^{\mathrm{a}}$ \\
Malonil glicitina & $41,6 \pm 0,3^{\mathrm{b}}$ & $14 \pm 2^{\mathrm{c}}$ & $8,9 \pm 0,7^{\mathrm{c}}$ & $80 \pm 8^{\mathrm{a}}$ \\
Acetil daidzina & $22,3 \pm 0,4^{\mathrm{b}}$ & $9,7 \pm 0,8^{\mathrm{c}}$ & $6,1 \pm 0,1^{\mathrm{d}}$ & $26 \pm 3^{\mathrm{a}}$ \\
Malonil genistina & $444 \pm 3^{\mathrm{b}}$ & $146 \pm 10^{\mathrm{c}}$ & $109 \pm 6^{\mathrm{c}}$ & $540 \pm 50^{\mathrm{a}}$ \\
Daidzeína & $35 \pm 2^{\mathrm{b}}$ & $72 \pm 5^{\mathrm{a}}$ & $21 \pm 2^{\mathrm{b}}$ & $69 \pm 20^{\mathrm{a}}$ \\
Acetil genistina & $38,5 \pm 0,8^{\mathrm{a}}$ & $23 \pm 1^{\mathrm{b}}$ & $13,5 \pm 0,3^{\mathrm{c}}$ & $26 \pm 5^{\mathrm{b}}$ \\
Genisteína & $31,3 \pm 0,5^{\mathrm{b}}$ & $67 \pm 5^{\mathrm{a}}$ & $27 \pm 2^{\mathrm{b}}$ & $32 \pm 7^{\mathrm{b}}$ \\
Total & $1500 \pm 20^{\mathrm{b}}$ & $690 \pm 40^{\mathrm{c}}$ & $590 \pm 20^{\mathrm{c}}$ & $2.600 \pm 200^{\mathrm{a}}$ \\
\hline
\end{tabular}

Resultados expressos como média (dp para $n=3$ ) Letras iguais na mesma linha indicam que os resultados não são significativamente diferentes para $\alpha=0,05$

As formas malonil glicosideos representam mais de $50 \%$ do total de isoflavonas na farinha desengordurada de soja, enquanto os $\beta$-glicosídeos predominam no resíduo, indicando conversão durante a extração alcalina (Figura 6). As formas agliconas, que representam somente $4,4 \%$ do total na farinha desengordurada de soja, perfazem $20 \%$ do total de isoflavonas do isolado protéico de soja, o que indica conversão por hidrólise durante o processo. O aumento do teor de isoflavonas agliconas no produto final também foi observado por WANG \& MURPHY [24] e WANG et al. [25].

O sobrenadante do processo apresenta percentual de formas malonil glicosídeos e glicosiladas em torno de $47 \%$, e somente $3,9 \%$ de isoflavonas agliconas. A diferença do perfil de distribuição entre isolado e sobrenadante pode ser atribuida à solubilidade das isoflavonas: as formas agliconas são menos solúveis em água que as formas glicosiladas e conjugadas. O perfil dos efluentes de processo (resíduo alcalino e sobrenadante) indica que, para sua recuperação e aproveitamento como fonte de isoflavonas, tais substratos poderiam ainda ser submetidos ao tratamento térmico e conversão enzimática, para aumento do teor de isoflavonas agliconas (altamente biodisponiveis) por conversão das formas glicosiladas e malonil glicosídeos.

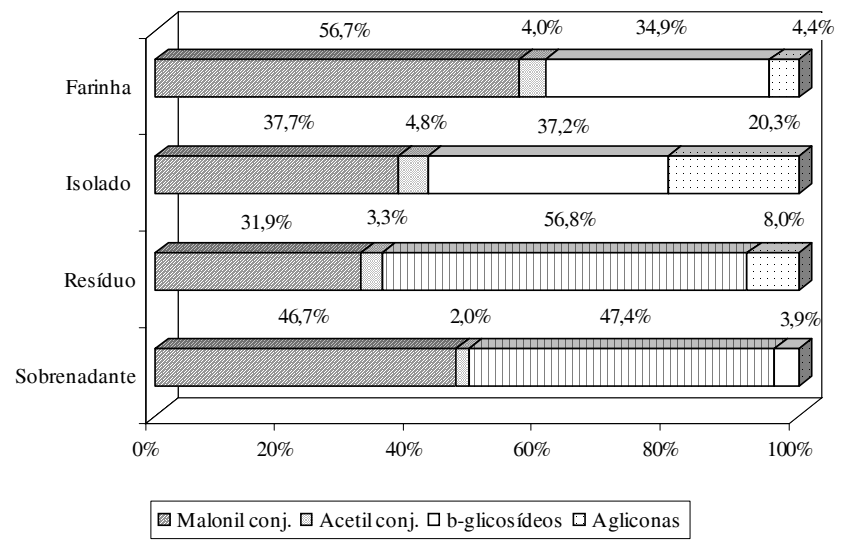

FIGURA 6. Distribuição percentual de formas de isoflavonas em correntes de processo para isolado protéico de soja

\section{1 - Concentrados protéicos de soja}

A retenção do total da proteína original para o produto obtido por tratamento com etanol é significativamente maior (Tabela 3) que a retenção no processo por tratamento ácido. Percebe-se ainda que ocorre maior perda de proteína no sobrenadante resultante do tratamento ácido que no sobrenadante por tratamento alcoólico. Os dois produtos obtidos correspondem à definição de concentrado protéico de soja, por apresentarem teor de proteína acima de $70 \%$, em base seca.

TABELA 3. Balanço de massa para proteínas em processamento de concentrado protéico de soja - tratamento ácido e alcoólico (etanol 60\%)

\begin{tabular}{|c|c|c|c|c|c|c|c|c|}
\hline \multirow[t]{2}{*}{ Corrente } & \multicolumn{2}{|c|}{ Massa total (g) } & \multicolumn{2}{|c|}{ Total proténa (g) } & \multicolumn{2}{|c|}{ \% proteína (b.s.) } & \multicolumn{2}{|c|}{ Retenção proteína (\%) } \\
\hline & \begin{tabular}{|l|} 
Ácida \\
\end{tabular} & Etanol & \begin{tabular}{|l|} 
Ácida \\
\end{tabular} & Etanol & Ácida & Etanol & Ácida & Etanol \\
\hline $\begin{array}{l}\text { Farinha } \\
\text { de soja }\end{array}$ & \multicolumn{2}{|c|}{50,0} & \multicolumn{2}{|c|}{$25,7 \pm 0,1$} & \multicolumn{2}{|c|}{$56,0 \pm 0,3$} & \multicolumn{2}{|c|}{100} \\
\hline $\begin{array}{l}\text { Concentrado } \\
\text { protéico }\end{array}$ & $34,4 \pm 0,3$ & $35,1 \pm 0,1$ & $24,0 \pm 0,1$ & $24,7 \pm 0,2$ & $72,7 \pm 0,4 \mathrm{a}$ & $72,6 \pm 0,4 \mathrm{a}$ & $93,4 \pm 0,4 \mathrm{~b}$ & $95,9 \pm 0,7 \mathrm{a}$ \\
\hline Sobrenadante & $926 \pm 1$ & $835 \pm 5$ & $1,9 \pm 0,4$ & $0,9 \pm 0,1$ & $15,2 \pm 0,1 \mathrm{a}$ & $8,5 \pm 0,3 \mathrm{~b}$ & $7,3 \pm 0,2 \mathrm{a}$ & $3,6 \pm 0,2 \mathrm{~b}$ \\
\hline
\end{tabular}

Embora o tratamento com álcool resulte em menores perdas de proteína no sobrenadante, ocorrem grandes perdas de isoflavonas (cerca de 90\%), que são muito solúveis em soluções alcoólicas (Figura 7). PANDJAITAN et al. [16], que quantificaram daidzina, genistina e suas respectivas agliconas em processos 
de obtenção de concentrado protéico chegaram a conclusão semelhante. O concentrado protéico obtido por esse método retém apenas $7,5 \%$ das isoflavonas presentes originalmente na farinha desengordurada de soja, apresentando $153 \mu \mathrm{g} / \mathrm{g}$ b.s., contra $41,7 \%$ de retenção do concentrado protéico obtido por precipitação com ácido, que contém $871 \mu \mathrm{g} / \mathrm{g}$ b.s. de isoflavonas ( $\mathrm{Ta}-$ bela 4).

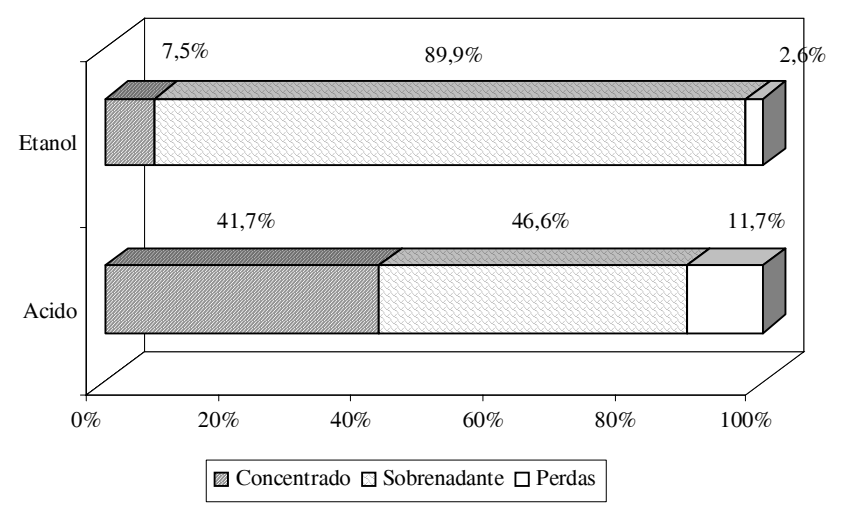

FIGURA 7. \% de retenção de isoflavonas em correntes de processo para concentrados protéicos de soja

TABELA 4. Balanço de massas de isoflavonas para processamento de concentrado protéico de soja

\begin{tabular}{|c|c|c|c|c|c|c|}
\hline \multirow[t]{2}{*}{ Corrente } & \multicolumn{2}{|c|}{ Isoflavonas totais (mg) } & \multicolumn{2}{|c|}{$\begin{array}{c}\text { Concentração } \\
\text { isoflavonas ( } \mu \mathrm{g} / \mathrm{g} \text { ) }\end{array}$} & \multicolumn{2}{|c|}{$\begin{array}{c}\text { Concentração isoflavonas } \\
(\mu \mathrm{g} / \mathrm{g} \text { b.s. })\end{array}$} \\
\hline & Ácida & Etanol & Ácida & Etanol & Ácida & Etanol \\
\hline Farinha de soja & \multicolumn{2}{|c|}{$69,1 \pm 0,8$} & \multicolumn{2}{|c|}{$1.370 \pm 20$} & \multicolumn{2}{|c|}{$1.500 \pm 20$} \\
\hline Concentrado protéico & $28,8 \pm 0,3$ & $5,18 \pm 0,01$ & $838 \pm 7$ & $147 \pm 1$ & $870 \pm 10$ & $153 \pm 1$ \\
\hline Sobrenadante & $32,2 \pm 0,8$ & $62,19 \pm 0,06$ & $35 \pm 1$ & $75 \pm 1$ & $2.590 \pm 30$ & $5.720 \pm 150$ \\
\hline
\end{tabular}

Resultados expressos como média \pm dp para $\mathrm{n}=3$.

Os dados a seguir (Tabela 5) ilustram o perfil de distribuição de isoflavonas para os dois processamentos de concentrado protéico de soja.

TABELA 5. Perfil de distribuição de isoflavonas para processamento de concentrados protéicos de soja ( $\mu \mathrm{g} / \mathrm{g}$ b.s.)

\begin{tabular}{|c|c|c|c|c|c|}
\hline \multirow[t]{2}{*}{ Isoflavona } & \multirow[t]{2}{*}{$\begin{array}{c}\text { Farinha de soja } \\
\text { ( } \mu \mathrm{g} / \mathrm{g} \text { b.s. })\end{array}$} & \multicolumn{2}{|c|}{$\begin{array}{c}\text { Concentrado protéico } \\
(\mu \mathrm{g} / \mathrm{g} \text { b.s. })\end{array}$} & \multicolumn{2}{|c|}{$\begin{array}{l}\text { Sobrenadante } \\
(\mu \mathrm{g} / \mathrm{g} \text { b.s. })\end{array}$} \\
\hline & & Ácido & Álcool & Ácido & Álcool \\
\hline Daidzina & $211 \pm 6^{\mathrm{c}}$ & $16 \pm 4^{\mathrm{d}}$ & $23,9 \pm 0,3^{\mathrm{d}}$ & $374 \pm 6^{b}$ & $821 \pm 9^{\mathrm{a}}$ \\
\hline Glicitina & $29,8 \pm 0,6^{\mathrm{c}}$ & $8,2 \pm 0,8^{d}$ & $2,5 \pm 0,1^{\mathrm{d}}$ & $80 \pm 1^{b}$ & $155 \pm 6^{\mathrm{a}}$ \\
\hline Genistina & $284 \pm 6^{c}$ & $66 \pm 8^{d}$ & $32,5 \pm 0,6^{\mathrm{d}}$ & $409 \pm 8^{b}$ & $1.990 \pm 40^{\mathrm{a}}$ \\
\hline Malonil daidzina & $367 \pm 2^{\mathrm{c}}$ & $144 \pm 3^{\mathrm{d}}$ & $33,6 \pm 0,3^{\mathrm{e}}$ & $754 \pm 3^{b}$ & $1300 \pm 50^{\mathrm{a}}$ \\
\hline Malonil glicitina & $41,6 \pm 0,3^{\mathrm{c}}$ & $19,9 \pm 0,3^{d}$ & $3,1 \pm 0,2^{\mathrm{e}}$ & $92 \pm 3^{b}$ & $174 \pm 5^{\mathrm{a}}$ \\
\hline Acetil daidzina & $22,3 \pm 0,4^{\mathrm{c}}$ & $20,2 \pm 0,7^{\mathrm{c}}$ & $2,5 \pm 0,2^{\mathrm{d}}$ & $50 \pm 2^{b}$ & $85 \pm 3^{\mathrm{a}}$ \\
\hline Malonil genistina & $444 \pm 3^{\circ}$ & $220 \pm 3^{d}$ & $43,4 \pm 0,8^{\mathrm{e}}$ & $660 \pm 10^{b}$ & $1.570 \pm 80^{\mathrm{a}}$ \\
\hline Daidzeína & $35,1 \pm 2^{d}$ & $156 \pm 5^{\text {a }}$ & $3,2 \pm 0,1^{\mathrm{e}}$ & $93 \pm 4^{c}$ & $139 \pm 6^{b}$ \\
\hline Acetil genistina & $38,5 \pm 0,8^{\mathrm{c}}$ & $50 \pm 1^{\mathrm{b}}$ & $4,7 \pm 0,5^{\mathrm{d}}$ & $42 \pm 2^{b}$ & $147 \pm 6^{\mathrm{a}}$ \\
\hline Genisteína & $31,3 \pm 0,5^{c}$ & $171 \pm 8^{a}$ & $3,3 \pm 0,1^{\mathrm{d}}$ & $39 \pm 3^{c}$ & $130 \pm 10^{b}$ \\
\hline Total & $1.500 \pm 20^{c}$ & $871 \pm 8^{d}$ & $152,2 \pm 0,9^{\mathrm{e}}$ & $2.590 \pm 30^{\mathrm{b}}$ & $5.620 \pm 150^{\mathrm{a}}$ \\
\hline
\end{tabular}

Resultados expressos como média \pm dp para $n=3$.

Letras iguais na mesma linha india \pm dp para n $=3$. diferentes para $\alpha=0,05$.

Analisando-se a Figura 8, verifica-se que o tratamento com álcool praticamente não alterou o perfil de isofla- vonas observado no concentrado protéico e no sobrenadante desse processo, havendo predominância das formas malonil glicosideos. Já o tratamento ácido promoveu redução dos teores das formas malonil, mais acentuadamente para malonil daidzina que para malonil genistina, indicando maior estabilidade desta última, fato que também foi observado por WANG et al. [25]. O percentual de $\beta$-glicosídeos do concentrado isoelétrico (obtido por tratamento com ácido) diminuiu em relação ao percentual da farinha, e houve grande aumento do percentual das isoflavonas agliconas daidzeina e genisteína, provavelmente por hidrólise no $\mathrm{pH}$ ácido de 4,5. Não foram detectadas as formas acetil glicitina e gliciteina em nenhum dos processos estudados. Novamente, verificou-se a predominância das formas malonil conjugadas e $\beta$-glicosídeos nos sobrenadantes dos dois processos.

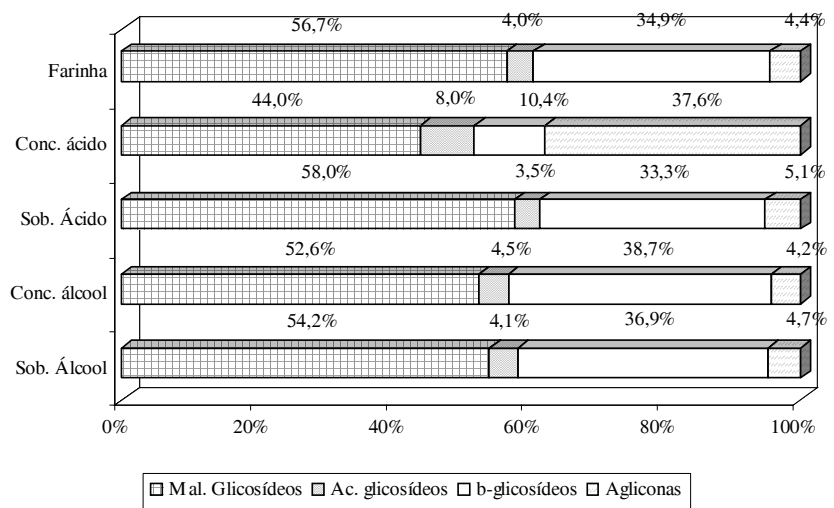

FIGURA 8. Distribuição das formas de isoflavonas em correntes de processo para concentrado protéico de soja

Vale ressaltar que no processamento industrial, ao contrário do processo em escala laboratorial adotado, os isolados ou concentrados protéicos de soja são submetidos a altas temperaturas na secagem (spray dryer ou tumble drying), o que pode promover conversão das formas malonil glicosídeos para acetil conjugadas.

Nota-se ainda que as quantidades não recuperadas de isoflavonas aumentam com o número de etapas do processamento, provavelmente por perdas de material retido nos equipamentos/vidrarias. As frações não recuperadas correspondem a $17,9 \%$ para processamento de isolado protéico, comparável com a fração indeterminada observada por WANG et al. [25] em processo semelhante, $11,7 \%$ para precipitação ácida e apenas $2,6 \%$ para precipitação com álcool. A diferença entre estes dois últimos processos pode ser atribuída a alta solubilidade das isoflavonas em soluções alcoólicas, o que diminui a probabilidade de retenção das isoflavonas em superficies apolares, como plásticos de tubos de centrifuga, seringas, etc.

\section{4 - CONCLUSÕES}

- Dentre os três ingredientes protéicos de soja obtidos, o concentrado protéico isoelétrico foi o que apresentou maior quantidade total de isoflavonas 
(871 $\mu \mathrm{g} / \mathrm{g}$ b.s.) e maior teor de isoflavonas agliconas $(327 \mu \mathrm{g} / \mathrm{g}$ b.s $)$, correspondendo a $37,6 \%$ do total de isoflavonas nesse produto.

- O processamento pode afetar grandemente a quantidade total e o perfil de distribuição das isoflavonas em suas formas conjugadas (malonil, acetil e $\beta$-glicosídeos) e agliconas. Tratamento com etanol $60 \%$ praticamente não alterou perfil de distribuição do concentrado protéico e de seu sobrenadante. Tratamentos com ácido promovem hidrólise, aumentando o teor das isoflavonas agliconas. As maiores perdas de isoflavonas nos processos estudados ocorrem nos sobrenadantes: $90 \%$ para processo de obtenção de concentrado protéico com etanol 60\%; 52\% para o processo de obtenção de isolado protéico e $47 \%$ para o processo obtenção de concentrado protéico isoelétrico.

- O isolado e concentrado protéicos de soja obtidos por precipitação ácida podem vir a ser meios de veicular isoflavonas na dieta, através de sua adição em produtos formulados. A contribuição dos concentrados protéicos obtidos por precipitação com álcool seria muito pequena.

- Os sobrenadantes dos processos são ricos em isoflavonas e proteína, e devem ser estudadas maneiras de promover a recuperação de isoflavonas, ou de diminuir a perda das mesmas nessas correntes de processo.

- O resíduo alcalino, composto de fibras e rico em proteina (38\% b.s.), contém razoável teor de isoflavonas. Se antes era destinado a ração animal, as empresas processadoras de soja já iniciaram processos para seu aproveitamento, seja na incorporação em proteínas texturizadas de soja, seja como fibras de soja.

- Tanto os ingredientes protéicos como os efluentes de processo podem sofrer tratamentos térmicos e enzimáticos de forma a converter as isoflavonas para as formas agliconas. Seria necessário também estudar a influência de tais tratamentos nas caracteristicas sensoriais e de funcionalidade tecnológica (retenção de água, capacidade emulsionante, espumante, etc.) dos ingredientes de soja obtidos.

\section{5 - REFERÊNCIAS BIBLIOGRÁFICAS}

[1] AOAC - Association of Official Analytical Chemists, Official Methods of Analysis, $16^{\mathrm{a}}$. ed., Washington D. C., Horwtis, W. (ed), 1997.

[2] ANTHONY, M.S.; ClARKSON, T.B.; BULlOCK, B.C. Soy protein versus soy phytoestrogens (isoflavones) in the prevention of coronary artery arteriosclerosis of cynomolus monkeys. Circulation, 94: abstract, 1996.

[3] BARNES, S.; KIRK, M.; COWARD, L. Isoflavones in soy foods: extraction conditions and analysis by HPLCMass Spectrometry. Journal of Agricultural and Food Chemistry, v. 42, p. 2466-2474. 1994.

[4] BURK, Z. Protein isolate. In. Technology of edible flours and protein products from soybean (3ª). Roma, FAO (UN), 1979. (FAO Agricultural Service Bulletin no. 11)

[5] CAMPBEll, M.F.; In AlTSChul, A.M.; WilCKe, H.L.E.D. New protein Foods, vol. 5, New York, Academic Press, p. 301-307. 1985.

[6] COWARD, L.; BARNES, N.C.; SETCHELL, K.D.R.; BARNES, S. Genistein, daidzein and their b-glucoside conjugates: Antitumor isoflavones in soybean foods from American and Asian diets. Journal of Agricultural and Food Chemistry, v. 41, n. 11, p. 1961-1967. 1993.

[7] COWARD, L.; SMITH, M.; KIRK, M.; BARNES, S. Chemical modification of isoflavones in soy foods during cooking and processing. American Journal of Clinical Nutrition, v. 68 (suppl.), p. 1486S-1491S. 1998.

[8] DALAIS, F.S.; RICE, G.E.; BELL, R.J. Dietary soy supplementation increases vaginal cytology maturation index and bone mineral content in postmenopausal women. American Journal of Clinical Nutrition, v. 68 (suppl.), p. 1518S. 1998.

[9] ELRIDGE, A.C. Determination of isoflavones in soybean flours, protein concentrates and isolates. Journal of Agricultural and Food Chemistry, v. 30, p. 353-355. 1982.

[10] GENOVESE, M.I.; LAJOLO, F.M. Determinação de isoflavonas em derivados de soja. Ciênc. Tecnol. Aliment., Campinas, v. 21, n. 1, p. 86-93, jan-abr. 2001.

[11] HOECK, J.; FEHR, W.R.; MURPHY, P.A.; WELKE, G.A. Influence of genotype and environment contents of soybean. Crop Science, v. 40, p. 48-51. 2000.

[12] KIM, H.; PETERSON T.G.; BARNES, S. Mechanism of action of the soy isoflavone genistein: emerging role for its effects via transforming growth factor signaling pathways. American Journal of Clinical Nutrition, v. 68 (suppl.), p. 1418S-1425S. 1998.

[13] KUDOU, S.; FLEURY, Y.; WELTI, D.; MAGNOLATO, D.; UCHIDA, T.; KITAMURA, K.; OKUBO, K. Malonyl isoflavone glycosides in soybean seeds (Glycine max MERRIL). Agricultural and Biological Chemistry, v. 55, n. 9, p. 2227-2233. 1991.

[14] MOLTENI, A.; BRISIO-MOLTENe, L.; PERSKY, V. In vitro hormonal effects of soybean isoflavones. Journal of Nutrition, v. 125, p. 751S-756S. 1995.

[15] MURPHY, P.A. Phytoestrogen content of processed soybean products. Food Technology, v. 36, n. 1, p. 60-64. 1982.

[16] PANDJAITAN, N.; HETTIARACHCHY, N.; JU, Z.Y.; CRANDALL, P.; SNELLER, C.; DOMBEK, D. Evaluation of genistin and genistein contents in soybean varieties and soy protein concentrate prepared with 3 basic methods. Journal of Food Science, v. 65, n. 3, p. 399-402. 2000a.

[17] PANDJAITAN, N.; HETTIARACHCHY, N.; JU, Z.Y. Enrichment of genistein in soy protein concentrate with $\beta$-glucosidase. Journal of Food Science, v. 65, n. 3, p. 403-407. 2000b.

[18] PARK, Y.K.; AGUIAR, C.L.; ALENCAR, S.M.; SCAMPARINI, A.R.P. Biotransformação de isoflavonas de soja. Biotecnologia, Ciência e Desenvolvimento, v. 20 , p. 12-14, maio/junho 2001.

[19] PARK, Y.K.; AGUIAR, C.L.; ALENCAR, S.M.; MASCARENHAS, H.A.; SCAMPARINI, A.R.P. Conversão de malonil-b-glicosil isoflavonas em isoflavonas glicosiladas presentes em alguns cultivares de soja brasileira. Ciênc. Tecnol. Aliment., Campinas, v. 22, n. 2, p. 130-135, maio-ago 2002. 
[20] POTTER, S.M.; BAUNG, J.A.; TENG, H.; STILLMAN, R.J.; SHAY, N.F.; ERDWAN, J.W. Soy protein and isoflavones: their effects on blood lipids and bone density in postmenopausal women. American Journal of Clinical Nutrition, v. 68 (suppl. 6), p. 1375S1379S. 1998.

[21] SETCHELL, K.D.R.; BROWN, N.M.; ZIMMERNECHEMIAS, L.; BRASHEAR, W.T.; WOLFE, B.E.; KIRSCHNER, A.S.; HEUBI, J.E. Evidence for lack of absorption of soy isoflavone glycosides in humans, supporting the crucial role of intestinal -metabolism for bioavailability. American Journal of Clinical Nutrition, v. 76, n. 2, p. 447-453. 2002.

[22] SONG, T.; BARUA, K., BUSEMAN, G.; MURPHY, P. A. Soy isoflavon analysis: quality control and a new internal standard. American Journal of Clinical Nutrition, v. 68 (suppl.), p. 1474-1479 S. 1998.

[23] VYN, T.J.; XINGHUA, Y.; BRUUSELMA, T.W.; JACKSON, C.C.; RAJCAN, I; BROUDER, S.M. Potassium fertilization effects on isoflavone concentrations in soybean (Glycine max (L.) Merr.).
Journal of Agricultural and Food Chemistry; v. 50, n. 12, p. 3501-3506. 2002.

[24] WANG, H.; MURPHY, P.A. Mass balance study of isoflavones during soybean processing. Journal of Agricultural and Food Chemistry, v. 44, p. 23772383. 1996

[25] WANG, C.; MA, Q.; PAGADALA, S.; SHERRAD, M.S.; KRISHNAN, P.G. Changes of isoflavones during processing of soy protein isolates. Journal of the American Oil Chemistry Society, v. 75 , n. 3, p. 337341. 1998.

[26] XU, X.; HARRIS, K.S.; WANG, H.; MURPHY, P.A.; HENDRICH, S. Bioavailability of soybean isoflavones depends upon gut microflora women. Journal of Nutrition, v. 125, p. 2307-2315. 1995.

[27] ZANGELMI, A.C.B.; TAGLIOLATTO, M.A.; DIAS, E.L.; LANGE, D.A. Produtos de soja, leite, farinha e outros. Secretaria da Indústria, Comércio, Ciência e Tecnologia do Estado de São Paulo, 1982, p. 1-9, 80-96. (Série Tecnologia Agroindustrial, vol. 10). 